\title{
Spatial and temporal differentiation in colonizing populations of Ceratitis capitata
}

\author{
ANNA R. MALACRIDA, CARMELA R. GUGLIELMINO*, GIULIANO GASPERI, \\ LORELLA BARUFFI \& RICCARDO MILANI \\ Dipartimento di Biologia Animale, Universitá di Pavia, Piazza Botta, 9, 27100 Pavia, and *Dipartimento di Genetica e \\ Microbiologia, Universitá di Pavia ed Istituto di Genetica e Biologia Evoluzionistica del CNR, Pavia, Italy
}

\begin{abstract}
Two ancestral populations (Kenya and Reunion), two Mediterranean (Procida and Sardinia) and one new American population (Guatemala) of Ceratitis capitata were examined by electrophoresis for genetic variability at 27 enzyme loci. Two ordination approaches (principal component analysis and a tree representation) and $F$-statistical analysis have been used to distinguish the various patterns of genetic variations and to infer the underline causes and their relative contribution to the total variation. Three main patterns of variation emerge from the data: geographical, annual and seasonal differentiation. A main part of intraspecific variability involves the differentiation of central (Kenya and Reunion) versus peripheral populations (the Meditterranean and the American populations). The analysis suggests that the genetic structure of these populations is correlated with the historical events of their colonization. The affinity of the Guatemalan population with the Kenyan one could be the result of a recent founding of this population from the source area (Africa). More ancient historical events of colonization characterize the two Mediterranean populations. Seasonal variation has been found in the Procida population and chiefly involves the $\mathrm{Mpi}$ locus. In the same population the genetic variation across years has a minimum in 1986 due to the release of sterile T-101 males.
\end{abstract}

Keywords: Ceratitis capitata, electrophoretic markers, genetic variability, geographical populations, seasonal variation, spatial and temporal differentiation.

\section{Introduction}

The Mediterranean fruit fly, Ceratitis capitata, is a polyphagous and multivoltine tropical species which in the last 100 years has spread from its supposed origin in Africa to a number of countries including the Mediterranean basin, parts of South and Central America and Australia (Fletcher, 1989a). Historically some of the spread of the medfly has been documented (Hagen et al., 1981). As this species seems to have travelled with man, it has been suggested that from its supposed origin (Southern Africa) it travelled from the east coast of Africa to the Mediterranean with the Arab trade (Maddison \& Bartlett, 1989). In the Mediterranean region the medfly exploits a great part of its biological potential because these areas offer an increasing number of host fruits owing to the introduction of new species of cultivars (Fimiani, 1989). The first record of this pest in the European Mediterranean area was in Spain in 1842 (De Breme, 1842) and in Italy (Calabria) in 1863 (Martelli, 1910). Gallo et al. (1970) reports the first record of its presence in the Americas in 1905 in Brasil.

With respect to colonization, we suggest that the world medfly populations can be divided into three main categories. (i) ancestral populations: from the African mainland, south of the Sahara, (ii) ancient populations: the Mediterranean populations; and (iii) new populations: the American populations. Information on dispersal and on colonization rate of this species (Fletcher, 1989b), coupled with knowledge of the genetic structure of natural populations (Milani et al., 1989), is crucial to gain an understanding of the life-history strategies which determine the rate of gene flow between different sub-populations, and in planning management strategies against the pest species. Despite its economic importance, the species is still poorly studied from the standpoint of population genetics. Intraspecific genetic differentiation is expected to be associated with the colonization history of C. capitata, despite the apparent morphological uniformity within this species (White, 1989). Previous 
studies have shown large genetic differences between introduced populations and African ones (Huettel et al., 1980; Gasperi et al., 1987; Gasperi et al., 1991). Such data have provided information on the relative contributions of selection, gene flow, genetic drift and geographical isolation on the genetic pattern of this species.

In this paper we examine two ancestral populations (Kenya and Reunion), two ancient populations from the Mediterranean (Procida and Sardinia) and one new population: Guatemala. The aim is to describe the pattern of geographical and temporal variation and to infer the causes determining the relative similarity of the medfly populations. Mediterranean populations are interesting because winter and summer generations develop under very different conditions. For the Procida population, therefore, temporal variation in allele frequencies was studied over several different months in four consecutive years (1983-1986) to determine if there was a change in local breeding structure and/or in the levels of genetic variation. Adaptation to overwintering constrains and to the type of host availability is a function of genetic plasticity of the species and may result in genetic differentiation of the Mediterranean populations.

\section{Materials and methods}

Populations of Ceratitis capitata. Two populations from the African region (Kenya and Reunion Isl.), two populations from the Mediterranean basin (Sardinia and Procida island in the Bay of Naples, Italy) and one American population (from Guatemala) were studied according to sampling opportunities.

African populations. The Kenya population was represented by four samples of pupae on coffee berries collected in August and October 1984 and in April and October 1988 on two farms near Nairobi. The population on Reunion Island was sampled four times; in October and December 1987, near St Denis and in February 1988 and in January 1990 in St Leu from pupae collected on Mimusops elengi (Sapotaceae).

Mediterranean populations. Procida is an island in the gulf of Naples (Italy) located $2.7 \mathrm{~km}$ from the mainland and with a total surface of $3.7 \mathrm{~km}^{2}$. On this island during the year the density of the medfly population is oscillatory, with a very low density phase in winter and early spring (December-April: 20 flies/ha), a medium density phase in May-July (200 adults/ha) and very high densities in August-September $(30,000$ adults/ha) (Cirio, 1974). The overwintering medfly population is composed mainly of larvae utilizing bitter orange as a host. Procida island was chosen as an experimental area to study the field performance of sterilized males from genetic sexing strains (Robinson, 1989) in a cooperative programme between ENEA (Italian National Committee for Research and Development of Nuclear Energy) and IAEA (International Atomic Energy Agency) for the control of medfly using the SIT method (Sterile Insect Technique) (Cirio et al., 1987). A total of 20.2 million sterile males from the strain T-101 (Seibersdorf, IAEA Laboratory) were released on the island of Procida from April 14 to July 13, 1986. The Procida population was sampled over seasons, and consequently over density phases, from 1983 to 1986 . A total of 22 samples comprising 751 specimens was obtained. The samples of 1986 were collected after the T-101 fly release. In July 1986 a sample of pupae was also collected on the adjacent mainland at Monte di Procida. The population from Sardinia was sampled for four consecutive years (October 1985, September 1986, September 1987, September 1989: two samples) in the Western and Eastern parts of Central Sardinia.

Collections of wild flies from these Mediterranean populations were made by harvesting infested fruits (peach, apricot, fig, bitter orange) from the ground beneath trees, and rearing the larvae in the laboratory.

American population. This population was sampled once in February 1989 from coffee berries from a farm near Antigua (Guatemala).

Electrophoretic studies. Preparation of samples and electrophoretic procedures are described by Gasperi et al. (1991). For each population sample at least 25 individuals were assayed at the following 27 enzyme loci: $\mathrm{Mpi}, \mathrm{Est}_{6}, \mathrm{Mdh}_{2}, \mathrm{Hk}_{2}, \mathrm{Est}_{1}, \mathrm{Est}_{2}, \mathrm{Pgi}, \mathrm{Zw}, \mathrm{Pgd}, \mathrm{Fh}$, Had, Hk $k_{1}$ Idh, Pgm, Got, Got $_{2}, A k_{2}, M d h_{1}, A d h_{2}$, Gpt, Pgk, Me, $\alpha$-Gpdh, Aox, Ak $k_{1}$, Acon $_{1}$, Acon $_{2}$. Staining for enzyme activities after electrophoresis was based on recipes of Meera Khan (1971) and Harris \& Hopkinson (1976). The loci $\alpha-G p d h, A o x, A k_{2}$, were monomorphic in all samples.

Data analysis. The measurement and testing of heterogeneity among samples from different geographical areas were carried out in different ways. $H_{\mathrm{S}}, H_{\mathrm{T}}, F_{\mathrm{IS}}$, $F_{\text {IT }}$ and $F_{\text {ST }}$ statistics were computed by the method of Nei \& Chesser (1983). The $F_{\mathrm{ST}}$ values were tested for departure from zero with the method of Workman \& Niswander (1970). Two ordination approaches have been used for electrophoretic data: principal component analysis and a tree representation. The rationale for applying principal component analysis to allele frequencies is given in Cavalli Sforza \& Bodmer (1971), and in Guglielmino et al., (1990). Principal 
component analysis (Sneath \& Sokal, 1973) is used to examine spatial patterns of association of populations. The method allows one to summarize the total variation among populations accounted for by the $N$ row variables in $N$ new, synthetic and orthogonal variables, few of which will hopefully explain a high proportion of the total variation.

Cluster analysis through a tree representation was performed using the BIOsYs-1 program of Swofford \& Selander (1981). The Cavalli Sforza \& Edwards (1967) chord genetic distance was used and from this distance measure, trees were constructed using Unweighted Pair-Group Arithmetic Average (UPGMA ) cluster analysis (Sneath \& Sokal, 1973).

\section{Results}

A tree obtained with Cavalli Sforza and Edwards' distances representing all the 36 samples from the two native (Kenya, Reunion) and three introduced populations (Sardinia, Procida and Guatemala) is shown in Fig. 1. Out of the 36 samples analysed, 22 belong to the Mediterranean Procida population and represent collections from different years and months. The main feature of this tree is the entangling of geographical and seasonal differentiation among the samples: Procida early season samples (April and February) appear separated by a major split, in between Reunion samples and Kenya-Guatemala samples.
Fig. 1 Tree representing the 36 samples of Ceratitis capitata. The genetic distances are calculated according to Cavalli Sforza \& Edwards (1967) and are based on all the allelic frequencies, including those of the $M p i$ locus.
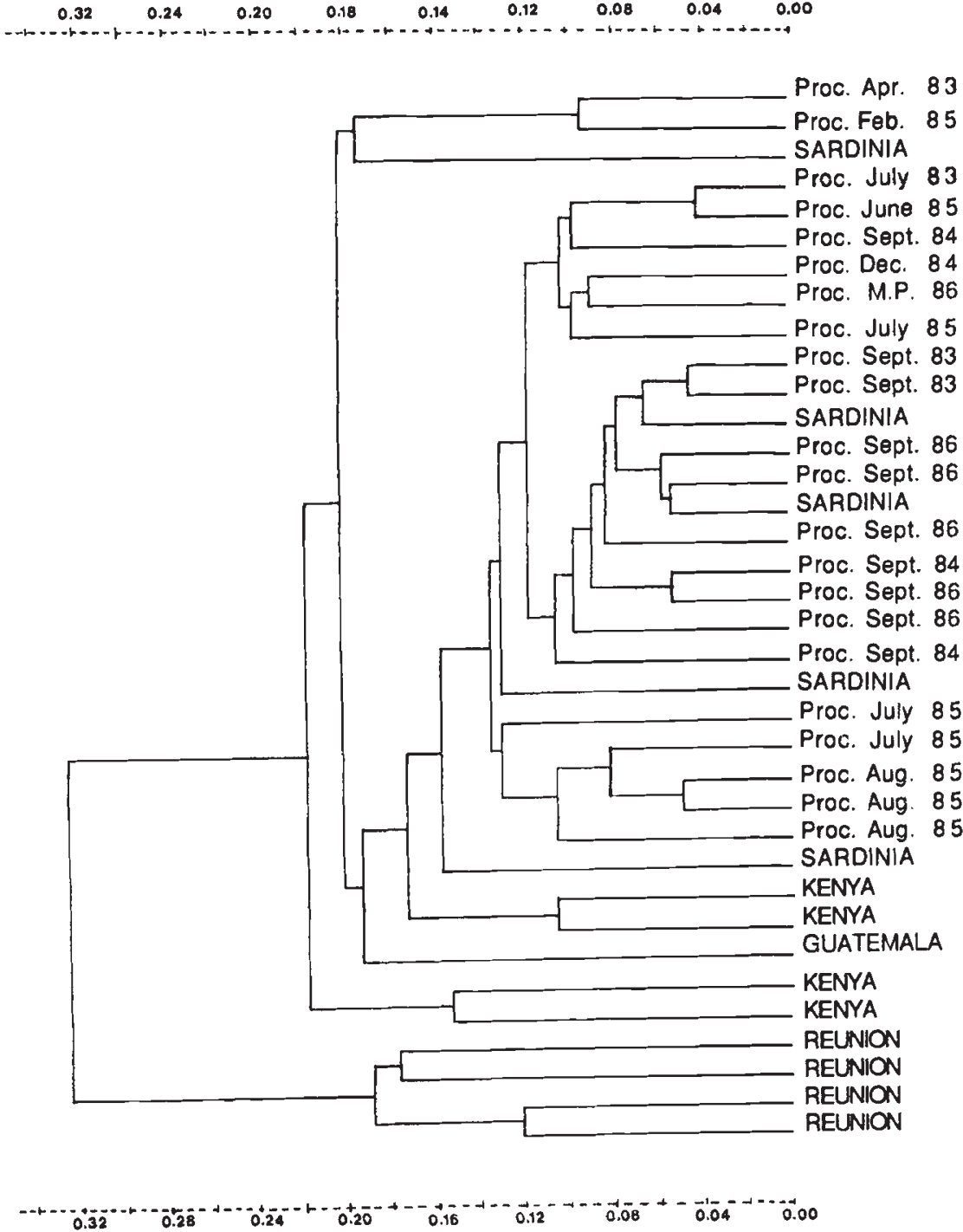

Cavalli Sforza and Edwards' distance 
Two systemic approaches, principal component analysis and estimates of genetic variability such as the $F$-statistics, are used in an attempt to distinguish the various patterns of genetic variation and to infer the underline causes and their relative contribution to the total variation.

\section{Principal component analysis}

The 36 population samples are plotted in Fig. 2 with respect to the first two principal axes, which together account for 49.2 per cent of the total variation in allele frequencies.

First principal component. The first principal component accounts for 34.8 per cent of the total variation. It separates samples mostly on a geographical basis: Reunion, Kenya and Guatemala appear on the right side of the plot, Procida samples generally occupy the left half while Sardinia samples are scattered in between. Geographical distance is clearly involved in the genetic differentiation of medfly populations. Reunion samples are the most differentiated; Kenya and Reunion, defined as ancestral populations, have similar scores on the first axis. A feature which distinguishes derived from native populations is the lower level of genetic variability of the former as expressed by the three statistics: $A$ (average number of alleles per locus), $P$ (proportion of polymorphic loci) and $H$ (average frequency of heterozygous individuals)

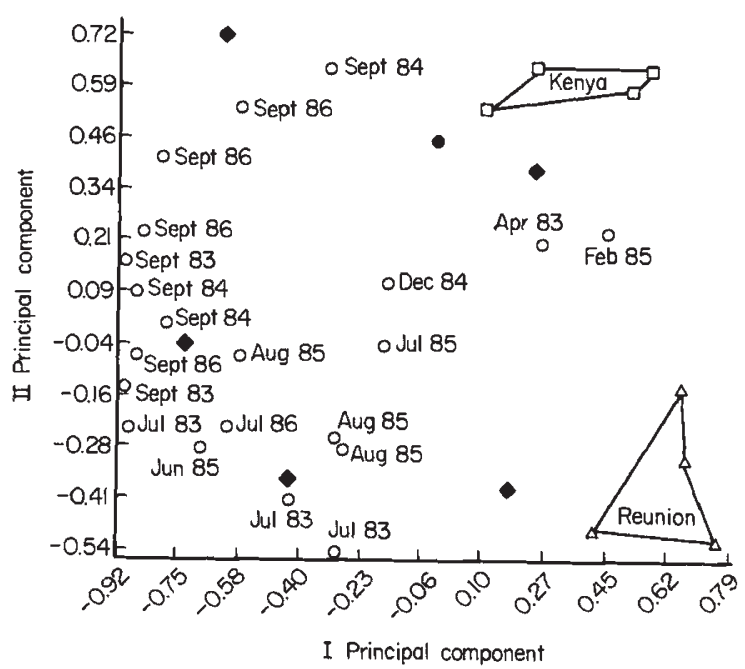

Fig. 2 Plot representing the 36 samples of $C$. capitata with respect to the first two principal axes obtained from the correlation matrix between populations. The first principal component ( $x$-axis) and the second principal component $(y$-axis) account for 35 and 14 per cent of the total variation, respectively. (O) Procida, ( ) Sardinia, $(\bullet)$ Guatemala, $(\square)$ Kenya, $(\Delta)$ Reunion.
(Table 1). An attempt to relate this genetic variability to the coordinates of samples along the first axis is shown in the correlation (Fig. 3) between the first principal coordinate and the parameter $H$ calculated for each sample. The correlation coefficient is highly significant $(r=0.73, \quad P \ll 0.001)$. A great part of variability expressed by the first component is due to the geographical differentiation in the species range, which in turn, is associated with the colonization process. However, the temporal heterogeneity present in the Procida samples also contributes to this part of total variation.

The Procida samples collected from 1983 to 1985 are distributed along the first axis with 1986 samples in between. Note that 1986 was the year in which the genetic sexing strain (T-101) was released in Procida: these samples represent the after-treatment rising population (Cirio et al., 1987). The average heterozygosity $(H)$, proportion of polymorphic loci $(P)$ and mean number of alleles per locus $(A)$, observed for each year in Procida samples, are presented in Table 2. The mean number of recorded heterozygous individuals doubled in a 3-year period from 1983 to 1985 (the difference is significant, $t_{(10)}=3.3,0.01>P>0.001$ ). The changes observed comprise new alleles at some loci $\left(A k_{2}, I d h, M d h_{1}, P g k\right)$ and variations in relative frequency for the alleles of other loci such as $E s t_{6}$ and $H k_{2}$. This data may indicate a trend of increasing variability in the Procida medfly population. However the relatively short period of observations and an unsystematic monthly sampling suggest that the interpretation should be treated with caution.

The mean heterozygosity value of the samples collected in 1986, after the release of the sexing strain, is similar to the one assessed in 1984. The lowering of the mean heterozygosity between the 1985 and 1986 samples is closed to statistical significance $\left(t_{(11)}=1.87\right.$, $0.10>P>0.05)$ and can be related to the release of sterile males. Two factors might have contributed to the lowering of this variability: (a) the preventive destruction of source oranges with the high polymorphic overwintering generation (Table 1) operated in the prerelease phase; (b) the impressive reduction in population size following the release phase (Cirio et al., 1987).

Second principal component. The second component accounts for 14.4 per cent of the total variation. At the geographical population level it reflects a degree of differentiation between the two African populations, Kenya and Reunion. Procida samples are distributed throughout the range of this axis and exhibit a slight seasonal trend. Wintering and early seasonal samples appear in the middle, July and August on the bottom, and September all over in the left top. Wintering and the early season (December, April, February) are also 
Table 1 Parameters of genetic variability in field-collected samples of Ceratitis capitata from five countries

\begin{tabular}{|c|c|c|c|c|c|}
\hline $\begin{array}{l}\text { Geographical origin } \\
\text { and host name }\end{array}$ & $\begin{array}{l}\text { Date of } \\
\text { collection }\end{array}$ & $A$ & $P$ & $H$ & ( \pm S.E. $)$ \\
\hline \multicolumn{6}{|l|}{ Procida } \\
\hline Bitter orange & Apr. 83 & 1.240 & 0.240 & 0.044 & $(0.021)$ \\
\hline Apricot & July 83 & 1.083 & 0.083 & 0.022 & $(0.017)$ \\
\hline Fig & Sept. 83 & 1.167 & 0.125 & 0.032 & $(0.018)$ \\
\hline Peach & Sept. 83 & 1.250 & 0.217 & 0.025 & $(0.013)$ \\
\hline \multicolumn{6}{|l|}{ Procida } \\
\hline Peach & Sept. 84 & 1.087 & 0.090 & 0.027 & $(0.019)$ \\
\hline Fig & Sept. 84 & 1.240 & 0.240 & 0.062 & $(0.025)$ \\
\hline Prickly-pear & Sept. 84 & 1.120 & 0.120 & 0.033 & $(0.019)$ \\
\hline Bitter orange & Dec. 84 & 1.240 & 0.240 & 0.047 & $(0.024)$ \\
\hline \multicolumn{6}{|l|}{ Procida } \\
\hline Bitter orange & Feb. 85 & 1.320 & 0.320 & 0.074 & $(0.025)$ \\
\hline Apricot & June 85 & 1.083 & 0.080 & 0.034 & $(0.024)$ \\
\hline Peach & July 85 & 1.240 & 0.240 & 0.076 & $(0.028)$ \\
\hline Peach & July 85 & 1.240 & 0.240 & 0.059 & $(0.023)$ \\
\hline Apricot & July 85 & 1.304 & 0.260 & 0.063 & $(0.025)$ \\
\hline Fig & Aug. 85 & 1.375 & 0.290 & 0.092 & $(0.032)$ \\
\hline Peach & Aug. 85 & 1.375 & 0.290 & 0.077 & $(0.029)$ \\
\hline Peach & Aug. 85 & 1.280 & 0.200 & 0.052 & $(0.025)$ \\
\hline \multicolumn{6}{|l|}{ Monte di Procida } \\
\hline Peach & July 86 & 1.440 & 0.360 & 0.071 & $(0.071)$ \\
\hline \multicolumn{6}{|l|}{ Procida } \\
\hline Persimmon & Sept. 86 & 1.291 & 0.292 & 0.065 & $(0.027)$ \\
\hline Peach & Sept. 86 & 1.400 & 0.360 & 0.051 & $(0.017)$ \\
\hline Peach & Sept. 86 & 1.210 & 0.210 & 0.044 & $(0.026)$ \\
\hline Persimmon & Sept. 86 & 1.052 & 0.052 & 0.016 & $(0.016)$ \\
\hline Persimmon & Sept. 86 & 1.273 & 0.227 & 0.049 & $(0.022)$ \\
\hline \multicolumn{6}{|l|}{ Sardinia } \\
\hline Plum & Oct. 85 & 1.391 & 0.304 & 0.114 & $(0.038)$ \\
\hline Fig & Sept. 86 & 1.261 & 0.261 & 0.073 & $(0.029)$ \\
\hline Fig & Sept. 87 & 1.360 & 0.280 & 0.066 & $(0.030)$ \\
\hline Peach & Sept. 89 & 1.385 & 0.308 & 0.062 & $(0.027)$ \\
\hline Pear & Sept. 89 & 1.231 & 0.192 & 0.048 & $(0.023)$ \\
\hline \multicolumn{6}{|l|}{ Reunion } \\
\hline Persimmon & Oct. 87 & 1.346 & 0.307 & 0.069 & $(0.025)$ \\
\hline M. elengi & Dec. 87 & 1.708 & 0.500 & 0.163 & $(0.043\rangle$ \\
\hline M. elengi & Feb. 88 & 1.565 & 0.384 & 0.109 & $(0.038)$ \\
\hline M. elengi & Jan. 90 & 1.481 & 0.333 & 0.083 & $\langle 0.039)$ \\
\hline \multicolumn{6}{|l|}{ Kenya } \\
\hline Coffee & Aug. 84 & 1.857 & 0.571 & 0.180 & $(0.050)$ \\
\hline Coffee & Oct. 84 & 1.880 & 0.640 & 0.166 & $(0.039)$ \\
\hline Coffee & Apr. 88 & 2.200 & 0.600 & 0.159 & $(0.043)$ \\
\hline Coffee & Oct. 88 & 2.077 & 0.461 & 0.149 & $(0.046)$ \\
\hline \multicolumn{6}{|l|}{ Guatemala } \\
\hline Coffee & Feb 89 & 1.154 & 0.077 & 0.039 & $(0.030)$ \\
\hline
\end{tabular}

separated along the first axis; in fact these sample collections are also the most polymorphic samples of Procida populations (Table 1). The existence of a correlation of the scores of Procida samples on the second component with the order of months from the beginning of the harvest season to the overwintering months has been tested. Regression analysis (Fig. 4) shows that a significant portion of the variance of the second principal component is explained by seasonality $\left(F_{(1)}=7.17, P<0.01\right)$. Analysis of variance (ANOVA II, 
Sokal \& Rohlf, 1981) shows that the means of the scores on the second axis for the most sampled months, July, August and September, are significantly different $\left(F_{(2,17)}=7.94, P<0.01\right)$. A consequence of this linear trend in the second axis with season is that a genetic discontinuity appears between the end of the overwintering generation and the beginning of the harvesting generation.

\section{F-statistics analysis}

All geographical populations. High $F_{\mathrm{ST}}$ values were previously found (Gasperi et al., 1991) at loci, Est $t_{1}$ $\left(F_{\mathrm{ST}}=0.613\right)$, Est $_{2}\left(F_{\mathrm{ST}}=0.685\right), H k_{2} \quad\left(F_{\mathrm{ST}}=0.219\right)$ and $\operatorname{Got}_{2}\left(F_{\mathrm{ST}}=0.183\right)$, when the subpopulations represented the geographical areas Kenya, Reunion, Procida and Sardinia. Other polymorphic loci, such as Mpi did not show differentiation at the geographical level. On the other hand, if the same data are analysed over time between months (i.e. when the subpopulations are the single month collections,) $M p i$ shows a

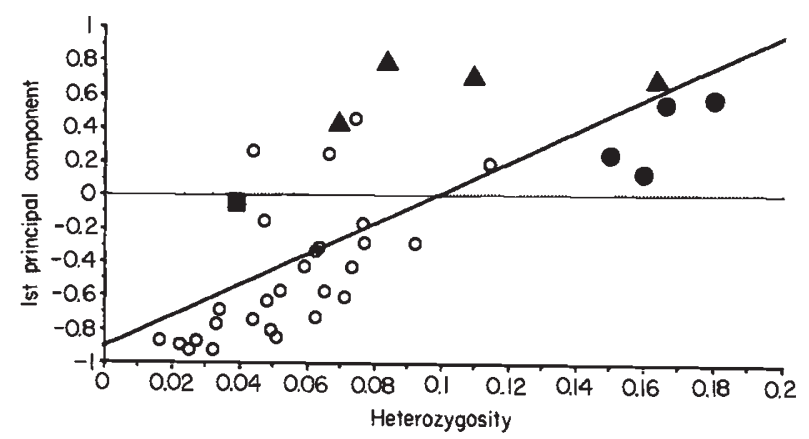

Fig. 3 Regression analysis between the heterozygosity measured for each of the 36 samples of $C$. capitata and their score relative to the first principal component. The correlation coefficient is 0.733 , with $P<0.001$. Ancestral populations: (•) Kenya; ( $\Delta$ ) Reunion. Ancient Mediterranean populations: unlabelled points. New American population: (घ) Guatemala. $y=9.207 x-0.905, R$-squared: 0.538 . degree of differentiation $\left(F_{\mathrm{ST}}=0.320\right)$, whereas no significant $F_{\mathrm{ST}}$ values are found at other loci. In this analysis the numerous Procida samples had the major load.

Procida population: genetic variation in time (years and seasons). The variance in allele frequencies of the 14 polymorphic loci was partitioned into variance among samples collected in different years (1983-1986) and across seasons. The temporal and seasonal pattern of variation in the Procida population is highlighted by the results shown in Tables 3 and 4. For each of the 14 polymorphic loci the heterozygosity of the pooled 22 Procida samples was partitioned into within years $\left(H_{\mathrm{S}}\right)$ and between years components $\left(H_{\mathrm{T}}\right)$ in Table 3 , and into within seasons $\left(H_{\mathrm{S}}\right)$ and across season components $\left(H_{\mathrm{T}}\right)$ in Table 4 . In both comparisons the proportion of heterozygosity attributable to differentiation is represented by the fixation index $F_{\mathrm{ST}}$ and the loci are arranged according to the linkage groups. It is quite clear when we compare the Procida samples across years, that there is little or no differentiation in terms of the fixation index for each of the 14 polymorphic loci. Most of the total gene diversity $\left(H_{\mathrm{T}}\right)$ is found within the collection of each year $\left(H_{\mathrm{S}}\right)$.

A very high degree of differentiation appears for the $M p i$ locus when the pooled samples of the 4 years are compared across seasons. Only 50 per cent of the total gene diversity for this locus $\left(H_{\mathrm{T}}=0.516\right)$ was found within each season $\left(H_{\mathrm{S}}=0.253\right)$. The $F_{\mathrm{ST}}$ value across seasons, for this locus, amounts to 0.509 , while the corresponding across-years value is 0.017 . The seasonal pattern of differentiation for the $M p i$ locus is also evident by comparing the samples across the seasons within a single year, 1985, $\left(F_{\mathrm{ST}}\right.$ for $M p i=0.457)$. Estimates of $F_{\text {IS }}$ and $F_{\text {IT }}$ for each of the polymorphic loci, have been done in the comparison of Procida samples across the seasons (Table 4 ); $F_{\text {IS }}$ and $F_{\text {IT }}$ estimate the deviation from panmixia within the seasons and across the seasons in this population. A very large positive value of $F_{\text {IT }}$ has been observed for

Table 2 Parameters of genetic variability of the Procida medfly population, as recorded in the years 1983-1985

\begin{tabular}{lllcl}
\hline Year & $\begin{array}{l}\text { Number of samples } \\
\text { examined }\end{array}$ & $H( \pm$ s.d. $)$ & $P( \pm$ s.d. $)$ & $A( \pm$ s.d. $)$ \\
\hline 1983 & 4 & $0.031(0.010)$ & $0.166(0.07)$ & $1.185(0.08)$ \\
1984 & 4 & $0.042(0.016)$ & $0.173(0.08)$ & $1.172(0.08)$ \\
1985 & 8 & $0.066(0.018)$ & $0.240(0.07)$ & $1.277(0.09)$ \\
1986 & & GS T-101 & Strain & \\
1986 & 5 & $0.045(0.018)$ & $0.228(0.11)$ & $1.245(0.13)$ \\
\hline
\end{tabular}


the $M p i$ locus $\left(F_{\mathrm{IT}}=0.617\right)$ and indicates a deficiency in heterozygotes for this locus. The $F_{\text {IT }}$ estimates for the other loci do not show marked deviations from panmixia, although for some of them there is significant

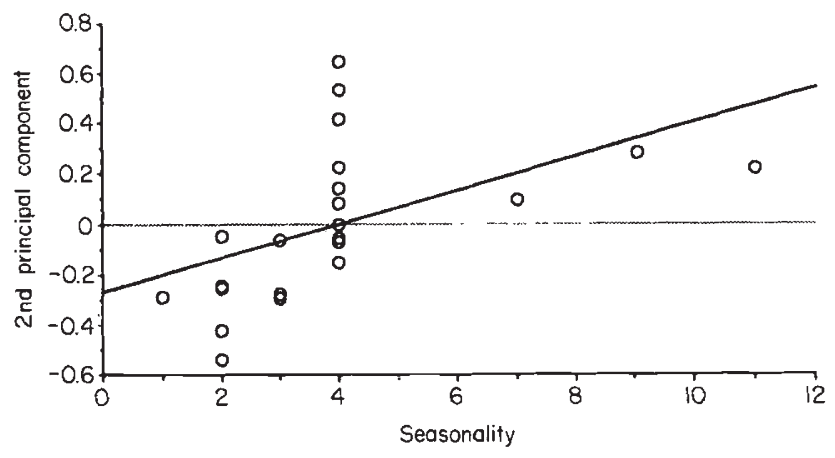

Fig. 4 Regression analysis between seasonality, expressed as the sequence of months from the beginning of the harvesting season, and the score relative to the second principal component, for the 22 Procida samples. Abscissa: 1, June; 2, July; 3, August; 4, September; 5, October; 6, November; 7, December; 8, January; 9, February; 10, March; 11, April; 12, May. The correlation coefficient is 0.514 , with $P<0.05$. $y=0.067 x-0.271, R$-squared: 0.264 . heterogeneity between season samples, as indicated by the $F_{\mathrm{ST}}$ heterogeneity chi-squared analysis. In the Procida population, there is a trend in the $M p i$ allele frequencies during the year as shown in Fig. 5. Only three samples (April 1983, December 1984, February $1985)$ represent the wintering season: in all three the $M p i^{105}$ allele appears with an unexpectedly high frequency.

Removing the Mpi locus. The dendrogram and the PCA plot in Fig. 1 and 2 portray the entangling of spatial and temporal variation in the medfly population. Procida samples exhibited statistically significant gene heterogeneity across the seasons at the Mpi locus, as seen from the $F_{\mathrm{ST}}$ analysis. When this locus is removed from the cluster analysis, the seasonal pattern disappears (Fig. 6a and b). In the tree of Fig. 6a the split sequences obtained from the remaining polymorphic loci provide evidence for a concordant geographical pattern of differentiation. No seasonal branching pattern is evident in the tree of Fig. 6a and in the principal component plot of Fig. $6 \mathrm{~b}$ the early season samples are not distinguishable from other Procida samples.

Table 3 Comparison of polymorphism in Procida population sampled in four successive years (1983-1986)

\begin{tabular}{|c|c|c|c|c|c|c|c|}
\hline Locus & $\begin{array}{l}\text { Number of } \\
\text { alleles }\end{array}$ & $H_{\mathrm{S}}$ & $H_{\mathrm{T}}$ & $F_{\text {IS }}$ & $F_{\text {IT }}$ & $F_{\mathrm{ST}}$ & $\begin{array}{l}\text { Heterogeneity } \\
\chi^{2} \text { (d.f.) } \dagger\end{array}$ \\
\hline \multicolumn{8}{|c|}{ Linkage group D (chr. II) } \\
\hline$M p i$ & 3 & 0.345 & 0.351 & 0.380 & 0.390 & 0.017 & $7.5(6)$ \\
\hline$E s t_{6}$ & 3 & 0.264 & 0.282 & 0.099 & 0.158 & 0.065 & $14.4(6)^{*}$ \\
\hline$M d h_{2}$ & 2 & 0.006 & 0.006 & -0.007 & -0.002 & 0.005 & $2.1(3)$ \\
\hline \multicolumn{8}{|c|}{ Linkage group C (chr. III) } \\
\hline$M d h_{1}$ & 2 & 0.018 & 0.018 & -0.021 & 0.005 & 0.025 & $10.5(3)^{* *}$ \\
\hline \multicolumn{8}{|c|}{ Linkage group A (chr. IV) } \\
\hline$H k_{2}$ & 3 & 0.358 & 0.372 & -0.004 & 0.033 & 0.036 & $15.0(6)^{*}$ \\
\hline$E_{s t_{1}}$ & 2 & 0.050 & 0.050 & -0.066 & -0.050 & 0.015 & $6.5(3)$ \\
\hline$E s t_{2}$ & 2 & 0.028 & 0.029 & 0.028 & 0.030 & 0.003 & $1.1(3)$ \\
\hline$P g i$ & 2 & 0.004 & 0.004 & -0.255 & -0.251 & 0.003 & $1.3(3)$ \\
\hline \multicolumn{8}{|c|}{ Linkage group B (chr. V) } \\
\hline$Z w$ & 2 & 0.243 & 0.243 & 0.036 & 0.037 & 0.001 & $0.4(3)$ \\
\hline \multicolumn{8}{|c|}{ Linkage group E (chr. VI) } \\
\hline$I d h$ & 2 & 0.016 & 0.017 & -0.060 & -0.037 & 0.022 & $9.31(3)^{*}$ \\
\hline Pgm & 2 & 0.025 & 0.025 & -0.066 & -0.062 & 0.004 & $1.6(3)$ \\
\hline$G o t_{1}$ & 2 & 0.034 & 0.035 & 0.260 & 0.270 & 0.013 & $5.6(3)$ \\
\hline \multicolumn{8}{|c|}{ Unmapped loci } \\
\hline$A k_{2}$ & 2 & 0.121 & 0.139 & 0.137 & 0.250 & 0.131 & $54.0(3)^{* * *}$ \\
\hline$P g k$ & 2 & 0.100 & 0.105 & -0.022 & 0.032 & 0.053 & $21.1(3)^{* * *}$ \\
\hline
\end{tabular}


Table 4 Comparison of polymorphism within and between pooled data of Dec. Apr./, June-Aug./Sept. samples of C. capitata collected in Procida during the years $1983-1986$

\begin{tabular}{|c|c|c|c|c|c|c|c|}
\hline Locus & $\begin{array}{l}\text { Number of } \\
\text { alleles }\end{array}$ & $H_{\mathrm{S}}$ & $H_{\mathrm{T}}$ & $F_{\text {IS }}$ & $F_{\mathrm{IT}}$ & $F_{\mathrm{ST}}$ & $\begin{array}{l}\text { Heterogeneity } \\
\chi^{2} \text { (d.f.) } \dagger\end{array}$ \\
\hline \multicolumn{8}{|c|}{ Linkage group D (chr. II) } \\
\hline$M p i$ & 3 & 0.253 & 0.516 & 0.220 & 0.617 & 0.509 & $225.5(4)^{* * * *}$ \\
\hline$E s t_{6}$ & 3 & 0.279 & 0.298 & 0.126 & 0.180 & 0.062 & $13.4(4)^{* * *}$ \\
\hline$M d h_{2}$ & 2 & 0.006 & 0.006 & -0.112 & -0.113 & 0. & - \\
\hline \multicolumn{8}{|c|}{ Linkage group C (chr. III) } \\
\hline$M d h_{1}$ & 2 & 0.020 & 0.020 & 0.006 & 0.024 & 0.018 & $7.2(2)^{*}$ \\
\hline \multicolumn{8}{|c|}{ Linkage group A (chr. IV) } \\
\hline$H k_{2}$ & 3 & 0.351 & 0.364 & -0.078 & -0.037 & 0.037 & $15.4(4)^{* * *}$ \\
\hline$E_{s t} t_{1}$ & 2 & 0.072 & 0.073 & -0.058 & -0.056 & 0.002 & $0.9(2)$ \\
\hline$E_{s t_{2}}$ & 2 & 0.045 & 0.046 & -0.107 & -0.080 & 0.024 & $9.1(2)^{* *}$ \\
\hline$P g i$ & 2 & 0.005 & 0.005 & 0.285 & 0.285 & 0.001 & $0.4(2)$ \\
\hline \multicolumn{8}{|c|}{ Linkage group B (chr. V) } \\
\hline$Z w$ & 2 & 0.260 & 0.262 & 0.113 & 0.120 & 0.007 & $2.5(2)$ \\
\hline \multicolumn{8}{|c|}{ Linkage group E (chr. VI) } \\
\hline$I d h$ & 2 & 0.037 & 0.038 & -0.076 & -0.053 & 0.021 & $8.9(2)^{* *}$ \\
\hline$P g m$ & 2 & 0.028 & 0.028 & 0.058 & 0.058 & 0. & - \\
\hline$G o t_{1}$ & 2 & 0.021 & 0.021 & 0.146 & 0.149 & 0.002 & $0.8(2)$ \\
\hline \multicolumn{8}{|c|}{ Unmapped loci } \\
\hline$A k_{2}$ & 2 & 0.121 & 0.137 & 0.132 & 0.232 & 0.115 & $47.4(2)^{* * * * *}$ \\
\hline$P g k$ & 2 & 0.071 & 0.073 & 0.010 & 0.044 & 0.034 & $13.6(2)^{* * *}$ \\
\hline
\end{tabular}

$* 0.02<P<0.05$.

${ }^{* *} 0.01<P<0.02$.

$* * * 0.001<P<0.01$

**** $P<0.001$.

$†$ The heterogeneity chi-square measures the significance of $F_{\mathrm{ST}}$.
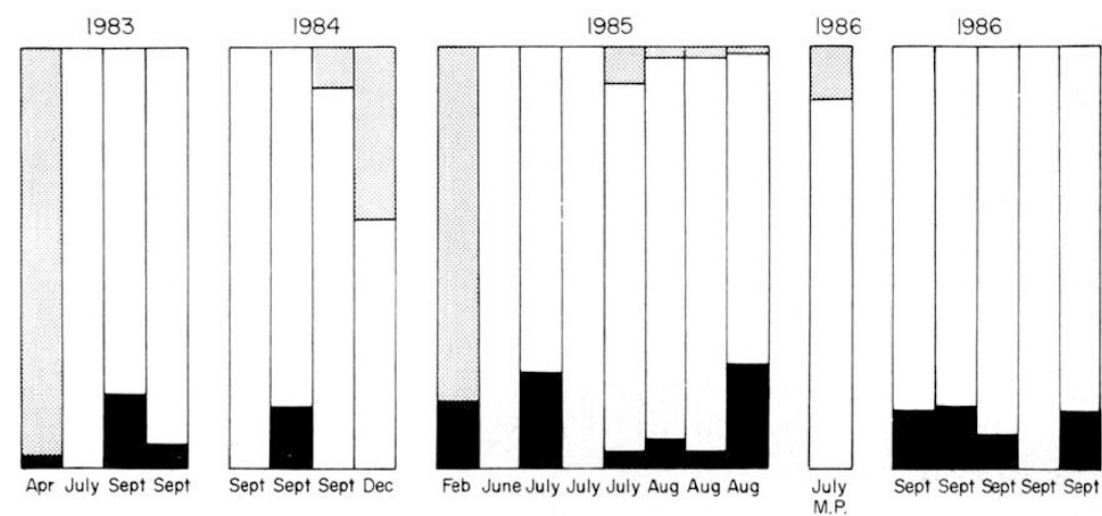

Fig. 5 Distribution of $M p i^{105}($ 田), $M p i^{111}(\bullet)$ and $M p i^{100}(\square)$ alleles locus in different years and months in the Procida population. In the winter months (February, April and December) the $M p i^{105}$ allele was found with frequencies ranging between 0.409 and 0.975 . In the other months the range was from 0.0 to 0.125 .

\section{Discussion}

In synthesis three main patterns of variation emerge from the present data on $C$. capitata: geographical, annual and seasonal differentiation.

\section{Geographical differentiation}

C. capitata is a fast colonizing species and a relatively newly imported pest from a source area localized in central Africa. In the plots of Fig. 6a and b genetic distances between African, European and American populations are the results of a sequence of historical events during the colonization process. A main part of intraspecific variability involves the differentiation of central versus peripheral populations. Reunion samples are the most differentiated, although they maintain the genetic attribute, together with the Kenyan ones, of an ancestral population, i.e. high variability (Gasperi et al., 1991). The affinity of Kenya 
(a)

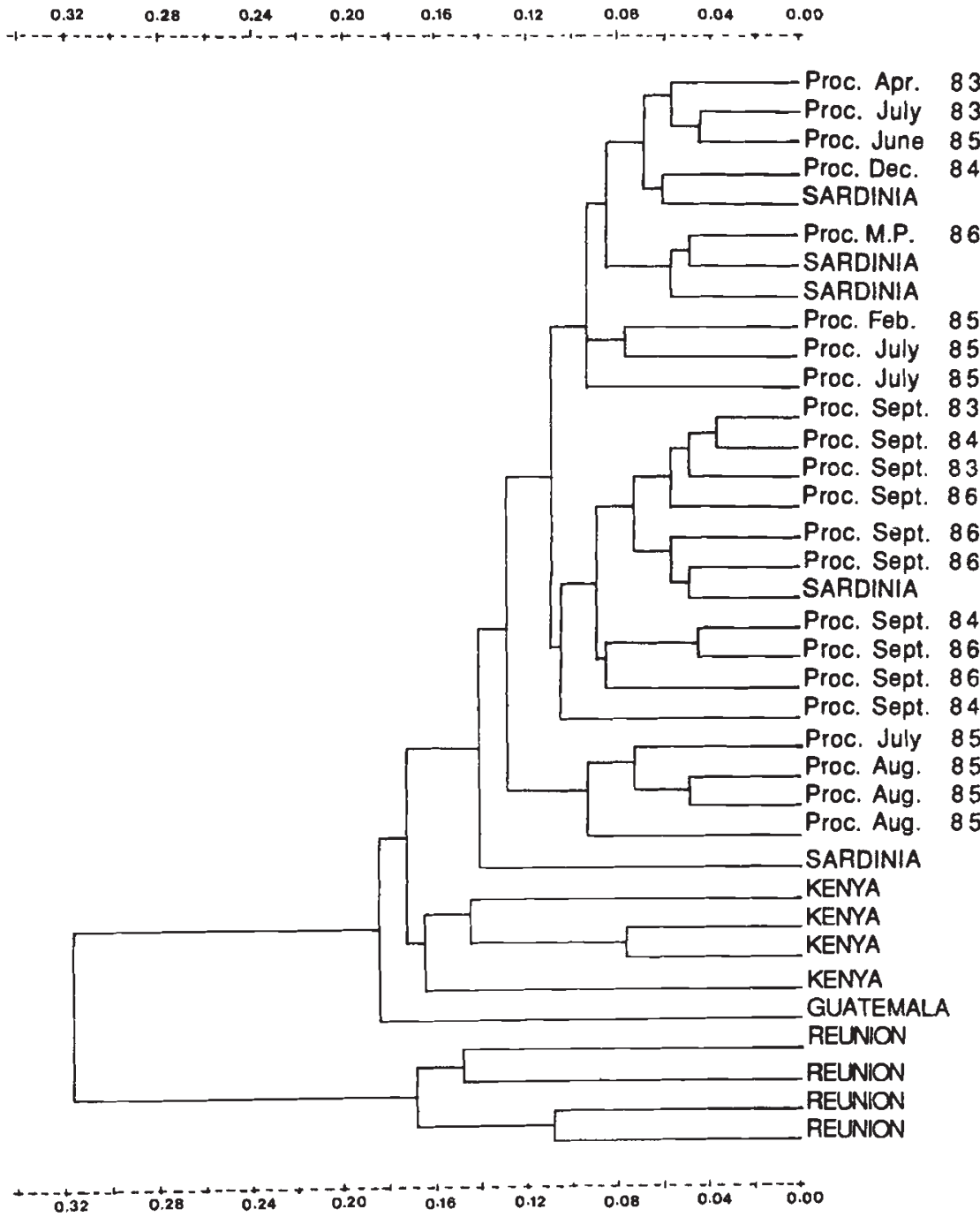

Cavalli Sforza and Edwards' distance

Fig. 6 Tree and principal component analysis of the 36 samples of $C$. capitata. Alleles of the Mpi locus are excluded from the computations. In (a) tree according to Cavalli Sforza and Edwards, (b) plot with respect to the two first principal axes. First and second principal components account for 37 and 17 per cent of the total variation respectively. $(0)$ Procida, $(\diamond)$ Sardinia, $(\bullet)$ Guatemala, (ㅁ) Kenya, $(\Delta)$ Reunion. (b)

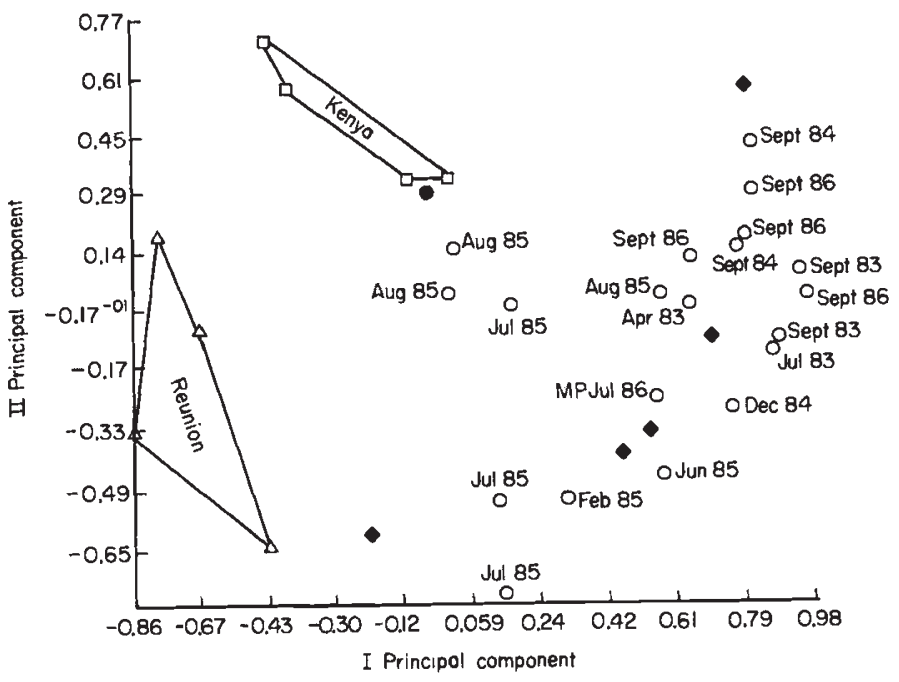


and Reunion is demonstrated by their vicinity both in the trees and in the PCA plots. The differentiation of Reunion, expressed by the second principal component and by the main split in the tree, can be correlated with the previous results (Gasperi et al., 1991) which support the hypothesis of founder effect and selection for the differentiation of this population. The affinity of the Guatemalan population with the Kenyan one could be the result of a recent colonization of Guatemala from the source area, although the fact that this population is represented by a single sample urges caution in interpretation. For this new population the extent of divergence could be related to the time of divergence because the oldest record of medfly in Latin America is dated around 1905 (Gallo et al., 1970). However, an hypothesis of the effect of common host plant specificity (coffee) with the Kenyan population must not be excluded. More ancient historical events of colonization (1863), (Firmiani, 1989) characterize the other two derived Mediterranean populations, Procida and Sardinia. Genetic analysis presented here supports the subdivision of these populations with respect to their history, as ancestral (Kenyan and Reunion), ancient (Mediterranean) and new populations (Guatemala).

\section{Seasonal and temporal differentiation}

In extending its geographical range, $C$. capitata faces new ecological constraints of a temperate climate, the most drastic of which is a cold winter. Mediterranean medfly populations experience seasonal cyclic variation because winter and summer generations develop under very different conditions. The anomalous allocation of cold seasons samples in the tree of Fig. 1, and the correlation of seasonality with the second principal component, both result from variation at the $M p i$ locus, which also shows very high $F_{\mathrm{ST}}$ values across seasons. The Procida population undergoes seasonal fluctuations with very low population densities in December-April and very high densities in late August-September (Cirio, 1974); therefore the observed gene diversity for the $M p i$ locus across seasons may relate to different density phase samples of this population. In a series of generations subjected to bottlenecks an increased $F_{\mathrm{ST}}$ is to be expected. The deviation from panmixia at the Mpi locus can hardly be attributed to inbreeding, given the absence of analogous indications for linked loci (Table 4). Nevertheless an inbreeding effect cannot be completely excluded because (a) in colder months, the population size reaches the minimum level and (b) gametes from closely related individuals are likely to combine in higher frequency than expected because of the aggrega- tion of individuals in a zone where food is available (bitter oranges only) (Cirio, 1974). In the winter season (December-April) the population size of Procida is probably close to the effective population size given its lowest density phase. A limited effective population size, under natural selection pressure, can speed the rate of increase of a selectively advantageous mutant (Kimura \& Ohta, 1971) across the seasons. Mpi codes for a function which controls the phosphorylation of mannose. A purely speculative hypothesis is that among the allozymatic forms coded for by the $M p i$ locus, a differential efficiency exists and that a more efficient form is selected to pass through the winter season $\left(M p i^{105}\right)$. The average value of heterozygosity across the years has a low value in 1986 , probably due to the release of sterile $\mathrm{T}-101$ males. Before this event the values of the genetic parameter $H$ generally increased from 1983 to 1985 , reaching an intermediate level of polymorphism also in the generation after the release. The increased level of heterozygosity over the years can be ascribed to the accumulation of new alleles. The new alleles may represent genes so rare before as to have escaped detection or they may reveal a high migration rate from the nearby mainland area (Cirio \& De Murtas, 1974).

Finally, from the methodological point of view we found a good correspondence between the phenetic approaches (principal component and tree analysis) and the hierarchial gene diversity analysis. Principal component analysis, in addition to its descriptive function, provided two synthetic indices of total genetic variability, i.e. the two first principal components, representing spatial and temporal variates of $C$. capitata. Complementary to this, $F$-statistical analysis allows the recognition of spatial or temporal difference between population subunits and identifies the genes mainly involved in the differentiation. In this respect, there is evidence for the presence of a seasonal Wahlund effect in the Mediterranean Procida population.

\section{Acknowledgements}

We would like to thank E. Zouros for critically reading and commenting on the manuscript. We are indebted to the following people for having provided the specimens studied: D. Lindquist and E. Bush-Petersen (IAEA, Vienna Austria); T. Mukiama (University of Nairobi, Kenya); S. Quilici (INRAT, Reunion, France); U. Cirio (ENEA, Rome, Italy) and G. Delrio (University of Sassari, Italy). We also thank an anonymous referee for diligent revision of the manuscript.

This research was supported by the National Research Council of Italy, Special Project RAISA, 
Sub-project No2, paper no. 279. Grants from MPI (fund 40 per cent from National Ministry of Education) and from IAEA (International Atomic Energy Agency, Vienna, Austria) also contributed to this work.

\section{References}

CAVAlli SFORZA, L. L AND BODMER, w. F. 1971. The Genetics of Human Populations. W. H. Freeman, San Francisco.

CAVAlli SFORZA, L. L. AND EDWARDS, A. W. F. 1967. Phylogenetic analysis: models and estimation procedures. Evolution, 21, 550-570.

CIRIO, U. 1974. Basi ecologiche per un programma di lotta contro la Ceratitis capitata Wied. nell'isola di Procida. Redia, 55, 189-201.

CIRIO, U., CAPPARELla, M. AND ECONOMPOUlos, A. P. 1987. Control of medfly (Ceratitis capitata Wied.) by releasing a mass-reared genetic sexing strain. In: Economopoulos, A. P. (ed.), Fruit Flies. Elsevier, Amsterdam, pp. 515-522.

CIRIO, U. AND DE MURTAS, I. D. 1974. Status of Mediterranean Fruit Fly control by the sterile-male technique on the island of Procida. IAEA, STI/PUB/364, 5-16.

DE BREME, F. 1842. Note sur le genre Ceratitis de M. Mac heay (Diptera). Ann. Soc. Entomol. France, 11, 183-190.

FIMIANI, P. 1989. Mediterranean Region. In: Robinson, A. S. and Hooper, G. (eds), Fruit Flies: Their Biology, Natural Enemies and Control, Vol. 3A, Elsevier, Amsterdam, pp. 37-50.

FLETCHER, B. S. 1989a. Life history strategies of tephritid fruit flies. In: Robinson, A. S. and Hooper, G. (eds), Fruit Flies: Their Biology, Natural Enemies and Control, Vol. 3B. Elsevier Amsterdam, pp. 195-208.

FLETCHER, B. S. 1989 b. Movements of tephritid fruit flies. In: Robinson, A. S. and Hooper, G. H. (eds), Fruit Flies: Their Biology, Natural Enemies and Control, Vol. 3B, Elsevier, Amsterdam, pp. 209-219.

GALlo, D. N. O., WJENDEl, F. M., Silveira NETO, S. AND RICARDO, P. L. C. 1970. Manual de Entomologia. Agronomica Ceres San Paulo.

GASPERI, G., GUGLIELMINO, C. R., MALACRIDA, A. AND MILANI, R. 1991. Genetic variability and gene flow in geographical populations of Ceratitis capitata (Wied.) (medfly). Heredity, 67, 347-356.

GASPERI, G., MALACRIDA, A. R. AND MillaNi, R. 1987. Protein variability and population genetics of Ceratitis capitata. In: Economopoulos, A. P. (ed.), Fruit Flies. Elsevier, Amsterdam, pp. 149-157.

GUGlielmino, C. R., PIAZZA, A., MENOZZI, P. AND CAVAlli SFORZA, L. L. 1990. Uralic genes in Europe. Am. J. Phy. Anthropol., 83, 57-68.
haGen, K. S., william, W. W. AND tassan, R. L. 1981. Mediterranean fruit fly: the worst may be yet to come. Calif. Agric. $35,5-7$.

HARRIS, H. AND HOPKINSON, D. A. 1976. Handbook of Enzyme Electrophoresis in Human Genetics. North-Holland Publ. Co., Amsterdam.

HUETTEL, M. D., FUERST, P. A., MARUYAMA, M. AND CHAKRABORTY, R. 1980. Genetic effects of multiple population bottlenecks in the mediterranean fruit fly (Ceratitis capitata). Genetics, 94s, 47-48 (abstract).

Kimura, M. ANd OHTA, T. 1971. Theoretical Aspects of Population Genetics. Princeton University Press, Princeton.

MADDISON, P. A. AND BARTLETT, B. J. 1989. Contribution towards the zoogeography of the Tephritidae. In: Robinson, A. S. and Hooper, G. (eds), Fruit Flies: Their Biology, Natural Enemies and Control, Vol. 3A. Elsevier, Amsterdam, pp. 27-35.

MARTELl, G. 1910. Alcune note intorno ai costumi e ai danni della Mosca delle arance (Ceratitis capitata, Wied.). Bol. Lab. Zool. Agr., Portici, 4, 120-127.

MEERA KHAN, P. 1971. Enzyme eletrophoresis on cellulose acetate gel: zymogram patterns in man-mouse and man-chinese hamster somatic cell hybrids. Arch. Biochem. Biophys., 145, 470-483.

MILANI, R., GASPERI, G. AND MALACRIDA, A. 1989. Biochemical Genetics (of Ceratitus capitata) In: Robinson, A. S. and Hooper, G. (eds), Fruit Flies: Their Biology, Natural Enemies and Control, Vol. 3B. Elsevier, Amsterdam, pp. 33-56.

NEI, M. AND CHESSER, R. K. 1983. Estimation of fixation indices and gene diversities. Ann. Hum. Genet., 47, 253-259.

ROBINSON, A. S. 1989. Genetic sexing methods in the Mediterranean Fruit Fly, Ceratitis capitata (Wiedman). In: Robinson A. S. and Hooper G. (eds), Fruit Flies: Their Biology, Natural Enemies and Control, Vol. 3B. Elsevier, Amsterdam, pp. 57-65.

SNEATH, P. H. A. AND SOKAL, R. R. 1973. Numerical Taxonomy. W. H. Freeman, San Francisco.

SOKAL, R. R. AND ROHLF, F. J. 1981. Biometry. W. H. Freeman, New York.

SWOFFORD, D. L. AND SELANDER, R. B. 1981. BIOSYS-1. A computer program for the analysis of allelic variations in genetics. University of Illinois, Urbana.

WHITE, I. M. 1989. The state of fruit fly taxonomy and future research priorities. In: Cavalloro, R. (ed.), Fruit Flies of Economic Importance 87. A. A. Balkema, Rotterdam, pp. 543-552.

WORKMAN, P. L. AND NISWANDER, J. D. 1970. Population studies on south western Indian tribes. II. Local genetic differentiation in the Papago. Am. J. Hum. Genet., 22, 24-49. 